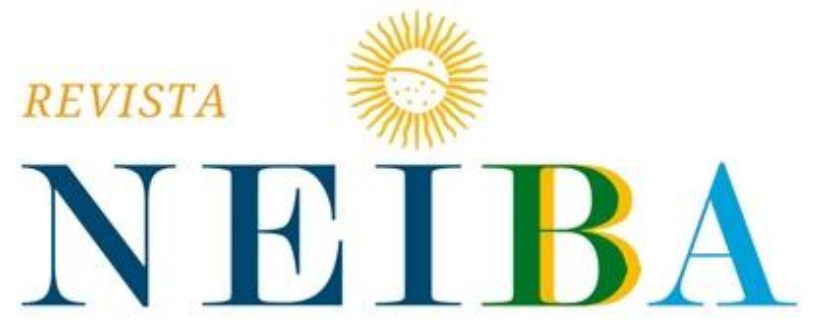

CADERNOS ARGENTINA-BRASIL
Volume 10,2021 , p. 01-15

DOI: 10.12957/neiba.2021.59053 | e59053 IISSN: 2317-3459

\title{
PARA UMA ANTIGA DIREITA, UM NOVO NACIONALISMO: UMA ANÁLISE SOBRE O FORTALECIMENTO DA EXTREMA DIREITA EUROPEIA E A INTENSIFICAÇÃO DE DISCURSOS XENÓFOBOS
}

\author{
FOR AN OLD RIGHT, A NEW NATIONALISM: AN ANALYSIS ON THE \\ STRENGTHENING OF EXTREME EUROPEAN RIGHT AND THE \\ INTENSIFICATION OF XENOPHOBIC DISCOURSES
}

\section{Carolina de Lima Costa ${ }^{1}$}

\section{Larissa Caroline Souza da Silva²}

${ }^{1}$ Universidade do Estado do Rio de Janeiro (UERJ), Rio de Janeiro, RJ, Brasil. E-mail: carolinalima1462@gmail.com. ORCID: https://orcid.org/0000-0002-4165-7602

2Universidade do Estado do Rio de Janeiro (UERJ), Rio de Janeiro, RJ, Brasil. E-mail: larissalarisouza@outlook.com. ORCID: https://orcid.org/0000-0003-0769-6971

Recebido em: 10/04/2021 | Aceito em: 01/10/2021.

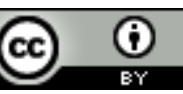

Esta obra está licenciada com uma Licença Creative Commons Atribuição 4.0 


\section{RESUMO}

Durante a segunda década do século XXI, é possível notar a maior proeminência de partidos de direita na Europa, que se fortalecem com base em discursos nacionalistas que exaltam a preservação de identidades estatais e fomentam narrativas anti-imigração. A proposta de leis mais rígidas quanto ao fluxo de pessoas feita pelo Ministro do Interior da Itália Matteo Salvini em nome da manutenção da segurança nacional e as declarações racistas proferidas pelo primeiro-ministro húngaro Viktor Orbán marcam a cena midiática internacional, expondo uma nova fase de políticas e posicionamentos orientados pelo que Denica Yotova (2017) chamou de "neonacionalismo". Sendo assim, o presente trabalho terá como objetivo estabelecer uma análise sobre a ascensão de partidos de direita em diversos países do bloco europeu e a emergência de discursos xenófobos. Para isso, discursos midiáticos recentes de governantes e candidatos direitistas serão considerados.

Palavras-chave: Neonacionalismo; Xenofobia; Direita Europeia.

\section{ABSTRACT}

During the second decade of the 21st century, it is possible to note the greater prominence of right-wing parties in Europe, which are strengthened on the basis of nationalist discourses that exalt the preservation of state identities and foster antiimmigration narratives. The proposal for stricter laws regarding the flow of people made by the Italian Interior Minister Matteo Salvini in the name of maintaining national security and the racist statements made by the Hungarian Prime Minister Viktor Orbán mark the international media scene, exposing a new phase of policies and positions guided by what Denica Yotova (2017) called "neonationalism". Thus, this paper aims to establish an analysis of the rise of right-wing parties in several European bloc countries and the emergence of xenophobic discourses. For this, recent media speeches by government officials and right-wing candidates will be considered.

Keywords: Neonationalism; Xenophobia; European Right-wing. 


\section{INTRODUÇÃO}

Em "Globalization, the welfare state and right-wing populism in Western Europe", Duane Swank e Hans-Georg Betz (2002) dissertam sobre o impacto do período pósindustrial, marcado pelo contexto internacional de globalização, na esfera doméstica dos Estados. Segundo os autores, os efeitos da globalização foram sentidos de maneiras distintas de uma nação para outra. Na medida em que algumas nações mantiveram a concessão de políticas de bem-estar social, mesmo diante das competitivas relações econômicas da globalização, para outros países, isto não foi possível; fato que gera insatisfações em cidadãos que, ao buscar soluções mais conservadoras, aproximam-se de partidos de extrema-direita.

Nos anos 2000, especialmente na segunda década, é possível notar o fomento de partidos de extrema direita no bloco europeu, que emergem em países como Itália e Espanha, trazendo à tona aspectos antigos que atacam questões relacionadas à integração a europeia e a presença de milhares de migrantes, que partem do Sul global em direção ao continente europeu. O migrante, neste caso, é visto como "o outro", o que vem de fora das linhas fronteiriças nacionais e que, por apresentar características etnoculturais distintas, não detém os mesmos direitos que os nacionais do Estado em questão (Walker, 2010).

\footnotetext{
Se há alguma novidade quanto à atitude intolerante ou xenófoba em relação a situações de intolerância no passado da história europeia, ela está na forma de organização e de articulação de ideias não democráticas. O voto na nova extrema-direita vem sendo também largamente interpretado como um voto de protesto do eleitor que está desacreditado e desconfiado dos políticos locais e nacionais, e que, naturalmente, não apoiaria a criação de mais instâncias políticas representativas ou decisórias - como as instituições europeias. (Tostes, p. 365)
}

Sendo assim, o presente trabalho tem por objetivo estabelecer reflexões acerca da relação entre ascensão dos partidos políticos europeus de direita, que se baseiam em discursos nacionalistas e a onda crescente de discursos racistas e xenófobos. Como destaca Soares et al (2020, p. 201), o cenário que se avista hoje não apenas nos países que formam a União Europeia (UE), mas em outros como Brasil e Estados Unidos com ascensão da extrema direita e discursos xenófobos não floresceu agora. Na verdade, a situação social, política e econômica criou as bases para tal acontecimento (Soares et al, 2020, p. 201). Dessa forma, a parte introdutória do artigo almejou contextualizar o meio 
político, econômico e social onde este tipo de discurso tem ganhado proeminência; a primeira seção do trabalho falará acerca da emergência da direita europeia, que é o foco do trabalho, sob um período marcado pelo neonacionalismo, conceito abordado por Yotova (2017); a segunda seção falará sobre o ressalto de ações e discursos xenófobos. E por fim, serão estabelecidas as considerações finais.

\section{OS NOVOS CONTORNOS DA EXTREMA DIREITA}

De 2007 para 2008, as ações do importante banco de investimentos estadunidense Lehman Brothers apresentaram um decréscimo de 95\%, afetando não só grandes empresas e bancos, como também cidadãos comuns ao redor do mundo, mesmo que de forma indireta, especialmente devido aos fundos de pensão ligados ao Lehman Brothers (BBC, 2008). Segundo Robert Keohane e Joseph Nye (1989, p. 15), "vivemos em uma era de interdependência", e desta maneira, crises de diversas naturezas promovem efeitos de maior alcance, afetando um grande número de Estados. Portanto, a instabilidade iniciada com a crise financeira na superpotência americana, gerou efeitos em diversas partes do mundo, especialmente em países do bloco europeu (Blikstad e Oliveira, 2018, p. 432).

\footnotetext{
A crise de 2008 explode em momento singular do capitalismo: pela primeira vez se está diante de um sistema mundial completamente integrado, a globalização se impõe enquanto "[...] fábrica de perversidade. O desemprego crescente torna-se crônico. A pobreza aumenta e as classes médias perdem a qualidade de vida. O salário médio tende a baixar. A fome e o desabrigo se generalizam em todos os continentes" (Santos, 2000, p. 10 citado por Soares et al., 2020, p. 211)
}

Se o sistema mundial está integrado e vive-se em uma era de interdependência, a crise de 2008 também atinge a União Europeia. A crise da zona do euro impactou consideravelmente o Produto Interno Bruto (PIB) das nações da União Europeia. Como pode ser visto no gráfico abaixo, há um declive referente ao ano de 2009, um ano após o início da crise que começou com a falência do Banco Lehman Brothers. 
Gráfico I - PIB (Produto Interno Bruto) dos países da União Europeia, entre os anos de 1999 e 2012

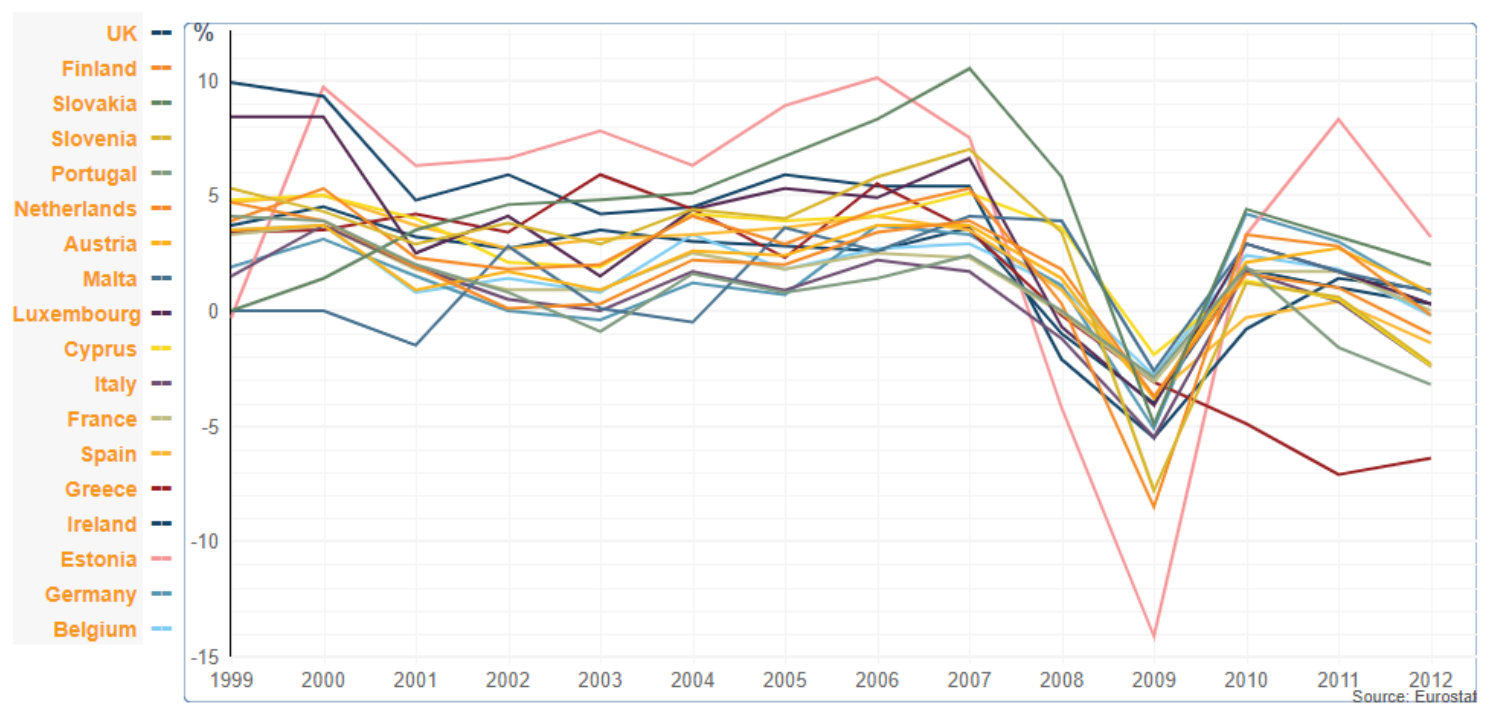

Fonte: Eurostat In: BBC (2013) "In graphics: Eurozone crisis".

Logo os efeitos da crise foram sentidos pelas populações civis. No primeiro capítulo de "A Europa Alemã", Urich Beck (2015) menciona a "geração crise", referente aos jovens afetados pelos índices de desemprego na Europa. Segundo Beck (2015, cap. 1), 1/4 dos cidadãos europeus com idade inferior a 25 anos não está empregada, na Grã-Bretanha o mesmo índice subiu 7\% desde o deslanchar da crise em 2008.

Perante o contexto de crise, as populações de alguns países europeus iniciaram uma série de manifestações e greves devido as altas quantias disponibilizadas pelos governos para recuperar instituições financeiras, prejudicando "o futuro das novas gerações" (Beck, 2015, cap.1). Em 2012, o Dia do Trabalho foi palco de diversas manifestações em Portugal, Grécia, França e Espanha, quando as populações se posicionaram contra as medidas que visavam cortes orçamentários (O Estadão, 2012).

Embora a crise financeira por si só não explique a emergência de partidos de extrema direita na Europa, esta trata-se de um fator relevante para compreender a insatisfação popular que de acordo com autores como Piero Ignazi (2003) e Ana Paula Tostes (2009) não são novas no contexto europeu, mas, nos anos 2000 acabaram por ser uma das justificativas, uma das bases que sustentam um sentimento de insatisfação quanto à União Europeia (UE), fortalecendo ideias eurocéticas².

\footnotetext{
2 O eurocetismo está relacionado ao sentimento de descrença na integração europeia e nas instituições do bloco. (Tostes, 2009, p. 355).
} 
Este novo tipo de partido, em vez de reviver o "mito palingenético" do fascismo, fornece uma resposta às demandas e necessidades geradas pela sociedade pós-industrial que os partidos tradicionais não conseguiram atender. Essas demandas e necessidades convergem na defesa da comunidade natural, em níveis nacional ou subnacional, da presença estranha e poluente - daí o racismo e a xenofobia - e responde à crise de identidade produzida pela atomização no nível social, pela globalização no nível econômico e pelo supranacionalismo no nível político. (Ignazi, 2003, p. 2, tradução nossa)

Soares et al (2020, p. 212) argumenta que os votos em partidos considerados parte da extrema direita aumentaram desde 2008 da mesma forma que ocorreu em outras crises anteriores, e que se pode perceber um fortalecimento de partidos de extrema direita em países como Estados Unidos, França, Áustria, Noruega e até mesmo Japão, e que eles ganham cada vez mais espaço nos governos. Essa "nova extrema direita" aponta soluções conservadoras para as mudanças geradas pelos processos globalizantes, tendo em vista que a globalização está relacionada a uma "compressão espaço-temporal" e tem como efeito a "interdependência acelerada (entendida como a intensificação do entrelaçamento entre economias e sociedades nacionais, de tal modo que os acontecimentos de um país têm um impacto direto em outros)." (Held e McGrew, 2001, p.11). Logo, a interdependência torna os Estados mais vulneráveis em relação ao que ocorre em outros países, especialmente quando os Estados compõem um bloco que preconiza uma união em níveis políticos, financeiros e sociais.

\subsection{O FORTALECIMENTO DA EXTREMA DIREITA EUROPEIA E O NEONACIONALISMO}

Como mencionado na seção introdutória deste artigo, diante do contexto de crise, discursos nacionalistas têm tomado mais espaço no cenário político europeu. Vemos atualmente um momento marcado por um espectro neonacionalista. Denica Yotova (2017, p. 64) define o conceito de neonacionalismo como

(...) o processo de reafirmação da nação e a fonte de legitimidade da comunidade étnica comum passado através de eventos selecionados de trauma nacional e glória nacional, símbolos, tradições, crenças e padrões culturais para explicar e justificar as ações atuais da elite política. (...) 0 conceito de neonacionalismo ou novo nacionalismo também está ligado ao surgimento de partidos de direita na Europa, movimentos antissistema, antiglobalismo, protecionismo, oposição à imigração e ao euroceticismo.

Na segunda parte da citação acima, a autora associa o neonacionalismo ao fortalecimento da extrema direita no bloco europeu, o que pode ser visto na realidade, já que nos anos que se seguiram ao início da crise econômica global, líderes de partidos 
direitistas têm conquistado mais espaço. Em 2010, Viktor Orbán foi eleito na Hungria, o partido conservador espanhol Vox ganha cada vez mais espaço e em 2018, obteve mais que o dobro de assentos parlamentares esperados em uma eleição regional (BBC, 2018b), e na Suécia, o aumento dos índices de criminalidade foi relacionado à entrada de imigrantes no país (BBC, 2018a).

Nos Países Baixos, por exemplo, Akkerman et al (2017) argumenta que apesar dos partidos de extrema direita e extrema esquerda serem populistas e possuírem algumas características em comum, quando se trata de tolerância aos imigrantes, o partido de extrema direita PRR (que possui expressão política no país) consegue mais votos de pessoas que possuem uma tendência contra os imigrantes. Dessa forma, as pessoas que votam na extrema direita nos Países Baixos geralmente são pessoas que possuem um discurso xenófobo ou que se alinham a um discurso contra o imigrante quando comparado com as pessoas que votam em outros partidos e em partido da extrema esquerda.

Nota-se, então, com tudo que foi abordado até aqui uma relação entre a emergência dos movimentos neonacionalistas e a conjuntura de crise econômica, posto que justamente na década posterior ao início da crise, os discursos nacionais e etnicamente centrados ganharam maior projeção e frequência, fato que também diz respeito à aceitação popular. Políticos de extrema direita que disseminam discursos racistas e/ou xenófobos não ocupariam cargos de grande responsabilidade caso a população não os elegesse, ou ao menos não partilhassem de suas opiniões conservadoras.

Em 2018, o primeiro-ministro húngaro, Viktor Orbán declarou que "nós não queremos que nossa cor seja misturada com outras cores" (ONU, 2018), o teor racista da declaração não impediu que o político permaneça no cargo por um período que já dura uma década (Heller, 2019). Assim como o discurso de Orbán, outras falas semelhantes que remetem ao racismo e a xenofobia apoiam-se em um argumento de segurança nacional. Em 2018, o então ministro do interior da Itália Matteo Salvini propôs leis severas anti-imigração, alegando que deveriam ser tomadas para que "a Itália seja mais segura" (Estadão, 2018). 
No capítulo conclusivo da obra de Michael Skey e Marco Antonsich (2017), os autores mencionam aspectos excludentes do nacionalismo. As características culturalmente compartilhadas, que representam pontos de convergência e unem grupos de indivíduos, também geram exclusão para outros coletivos, que não se encaixam nos aspectos que embasam a união do grupo étnico em questão. O movimento de supremacia branca na Suécia, por exemplo, exclui os cidadãos que não partilham dos mesmos traços físicos que pessoas brancas (BBC, 2018a).

Na citação acima, Skey e Antonsich (2017) falam acerca de hábitos rotineiros de exclusão. As práticas xenófobas que marcam a rotina política e social em alguns contextos no bloco europeu, demonstram um outro lado de um nacionalismo que, quando excludente, pode adquirir contornos de discriminação étnica e/ou racial, como pode ser visto nos posicionamentos conservadores supramencionados, tais como o de Viktor Orbán. Na próxima seção, falaremos mais amplamente sobre o conceito de xenofobia e as respostas dos governos europeus mais conservadores quanto à temática da imigração, reações governamentais articuladas com base em alicerces neonacionalistas, sustentados por autoridades e cidadãos comuns.

\section{SOBRE UMA NOVA ONDA DE XENOFOBIA}

Segundo o dicionário, o termo xenofobia refere-se à aversão ao que é estrangeiro, como efeito da aversão, discrimina-se os grupos nacionais de outro Estado. Em alguns casos, para justificar e dar corpo ao sentimento de aversão, atribui-se à identidade do estrangeiro características negativas e difamatórias. Os posicionamentos e opiniões xenófobas podem ser vistos tanto em discursos de representantes de partidos políticos, como também na população civil.

As atitudes e discursos que demonstram a aversão ao estrangeiro que caracteriza o conceito de xenofobia não tiveram início com os últimos acontecimentos relacionados ao es ministro Matteo Salvini. A xenofobia tem sido um fator que impulsiona conflitos civis e internacionais ao longo da história, como aconteceu na Guerra da Bósnia e no genocídio ruandês, ambos nos anos de 1990, eventos que geraram milhares de mortes e atos de violência com base em argumentos sobre diferenças étnicas e religiosas. 
Atualmente, em especial após os atentados de 11 de setembro, os adeptos da fé islâmica são frequentemente associados às práticas terroristas, um fator que gera atos de violência contra cidadãos islâmicos em várias partes do globo. As falas e medidas segregacionistas são direcionadas aos princípios da religião. Podemos ver um exemplo disso em 2004, quando uma lei francesa impediu que estudantes utilizassem o véu em escolas públicas e em 2011, quando o uso do véu foi proibido em espaços públicos. (The Guardian, 2013)

Nos arredores do bloco europeu, o preconceito contra os adeptos da fé islâmica também é notado. No fim de sua obra sobre nacionalismo russo, Pål Kolst $\varnothing$ (2016, p. 4041) relata que em uma pesquisa feita na Rússia em 2013, aproximadamente $60 \%$ dos entrevistados afirmaram que o "islamismo representa uma ameaça à estabilidade social e para a cultura russa", enquanto $48,7 \%$ demonstravam dúvidas sobre a honestidade das intenções dos povos imigrantes; aproximadamente metade dos entrevistados "opinaram que todos os imigrantes - não só aqueles sem permissão de trabalho apropriada - deviam ser deportados para seus países de origem". ${ }^{3}$

A extrema direita que ascende atualmente na Europa atribui automaticamente ao imigrante um status de ameaça nacional, o termo "automaticamente" foi empregado na frase já que o status de "risco" é estabelecido somente com base no fato de que aquele indivíduo é estrangeiro, mesmo sem que haja registros de antecedentes criminais que liguem os imigrantes em questão a atividades ilícitas. Apesar disso, o imigrante é apontado como um risco à estabilidade nacional em alguns discursos ultradireitistas, pelo simples fato de serem quem são, isto é, indivíduos imbuídos de características, físicas ou não, e valores culturais que os fazem parte de povos oriundos de uma nação exterior.

A justificativa de Matteo Salvini, já mencionada neste texto, também embasa suas declarações anti-imigração sobre supostos riscos que o fluxo migratório poderia trazer à segurança dos cidadãos da Itália (Estadão, 2018). Neste contexto, alguns coletivos étnicos são exaltados em relação a outros e, sendo a supremacia de um povo relacionada

\footnotetext{
${ }^{3}$ Embora a Rússia não faça parte da União Europeia, a obra de Pål Kolst $\varnothing$ (2016) sobre nacionalismo russo foi citada neste trabalho com o objetivo de exemplificar a aceitação de discursos xenófobos pela população civil.
} 
à "pureza étnica" de seus nacionais, a miscigenação é declarada como inaceitável para líderes como o húngaro Viktor Orbán (ONU, 2018).

Em 2018, o governo italiano se recusou a receber uma embarcação de resgate liderada por membros das organizações não-governamentais SOS Mediterranée e Médicos Sem Fronteiras, que resgatou e assistiu 600 indivíduos que migraram através do Mediterrâneo em direção a Europa, em busca de refúgio (Verdú, 2018). Esta reação do governo italiano vai contra aos artigos $2^{\circ}$ e $3^{\circ}$ da Convenção Europeia de Direitos do Homem, artigos que falam acerca do direito à vida e a tratamentos dignos, afirmando que "ninguém pode ser submetido a torturas, nem a penas ou tratamentos desumanos ou degradantes" (Corte Europeia de Direitos Humanos, 1950, art. $3^{\circ}$ ).

Em 2019, o então ministro italiano esteve envolvido em uma questão com outra ONG de resgate: a Sea-Watch, quando a capitã Carola Rackete - ativista da organização atracou na costa italiana mesmo diante da recusa de Matteo Salvini em receber os migrantes a bordo. A capitã comentou que assim o fez porque "a situação era desesperadora, meu objetivo era apenas trazer pessoas exaustas e desesperadas para a costa" (CNN, 2019). Nas palavras da capitã para o jornal El País (2019), há uma demanda urgente por posicionamento das autoridades e populações europeias em relação à questão migratória.

A situação está extremamente polarizada. Vemos isso também no Reino Unido e na Alemanha. O futuro nos dirá para onde vai a Europa, mas aqueles que estão no meio em silêncio devem levantar suas vozes. As pessoas que não se manifestaram devem se posicionar. E teremos que entrar em um acordo que a vida das pessoas tem o mesmo valor, independentemente de onde venham. É hora de que a parte central da sociedade contenha essa polarização e se coloque do lado do direito internacional. (Rackete, 2019)

Tendo em vista que nos casos mencionados as embarcações de resgate estavam compostas por cidadãos que passavam por situações de risco, rejeitá-las significa negligenciar o fato de que os migrantes em resgate poderiam não sobreviver caso as operações de salvamento não fossem completamente efetuadas. Embora países como a Alemanha apresentem uma postura mais receptiva quanto a entrada de refugiados ${ }^{4}$, as últimas declarações e respostas de alguns países do bloco quanto à questão migratória,

\footnotetext{
${ }^{4}$ Segundo Dados de 2020 da Agência das Nações Unidas para Refugiados (ACNUR), a Alemanha é o terceiro país que mais recebe refugiados no mundo.
} 
como a Itália, a Hungria de Viktor Orbán revelam a emergência de uma nova fase, marcada por posicionamentos conservadores e novas maneiras de fazer política, que apresenta contornos neonacionalistas, discriminatórias e xenófobas.

\section{CONSIDERAÇÕES FINAIS}

A proeminência de discursos xenófobos não é um fenômeno novo na Europa, já que a aversão ao que é estrangeiro e/ou diverso é parte de muitos episódios da história do velho mundo, tais como o nazismo e os conflitos étnicos que ocorreram na Bósnia na década de 1990. A exclusão de um outro grupo que não seja o nacional, de certa forma, faz parte do processo de construção de uma identidade nacional e do sentimento de pertencimento à uma nação ou à uma comunidade. Afinal, dentro dela vive um coletivo que remete seus nacionais a "nós" e lá fora o "outro".

Anderson (2008) apresenta o argumento de que toda nação é uma "comunidade imaginada", construída e pensada gradativamente desde a formação dos Estados-Nação, no século XVIII. Ao pensar um território composto por pessoas que possuem vínculos em um determinado espaço e tempo, é preciso distinguir esses grupos de outros e protegêlos de indivíduos vistos como estranhos, isto é, que divergem da identidade nacional. Contudo, proteção e distinção não implicam necessariamente em xenofobia e práticas contra imigração.

Mesmo com todos os acontecimentos recentes na Europa, com a expansão da União Europeia desde o final dos anos de 1990 e do passado europeu, os discursos xenófobos ganham espaço na Europa do século XXI e perante a intensificação deste tipo de discurso, a finalidade do presente trabalho foi estabelecer uma análise acerca da proeminência de falas segregacionistas e securitizantes ${ }^{5}$ direcionadas aos imigrantes, fortalecidas e disseminadas pela direita europeia na atualidade. Embora o fortalecimento de partidos ultradireitistas refira-se a um momento relativamente novo, que teve início há poucos anos, é possível perceber a insistência com que se coloca, já durando uma década,

\footnotetext{
${ }^{5}$ Segundo Ole Wæver (1998, p. 25), securitização é o processo pelo qual atribuímos a algo ou a alguém um status de uma questão de segurança, isto é, em algo que deve ser combatido, posto que representa uma "ameaça existencial" e pode causar "efeitos políticos substanciais". No caso deste artigo, o termo "securitizantes" referiu-se aos discursos que que tornam o imigrante uma questão de segurança nacional.
} 
ganhando espaço, sem inibições ou manifestações populares significativas que enfraqueçam as declarações de discriminação.

Portanto, podemos relacionar a ascensão da direita europeia ao aumento de discursos e respostas estatais xenófobas e racista na medida em que diante de uma conjuntura caótica, a direita europeia emergiu com soluções conservadoras para um momento de incertezas e déficit econômico, valendo-se deste contexto para propagação de antigas ideias discriminatórias.

Obviamente, os partidos ultradireitistas em ascensão nos últimos anos não criaram os discursos xenófobos, mas por meio de suas falas e ações, possibilitam que animosidades populares despertem com mais força, alcance e representatividade; já que por serem alicerçados por líderes políticos, pensamentos e discursos xenófobos ganham mais legitimidade, fato que confere maior frequência a falas de cunho xenófobo e/ou racista. Desta maneira, uma antiga direita, com as reivindicações conservadoras usuais, tem dado forma aos efeitos do que Denica Yotova (2017) referiu-se como novo ou neonacionalismo.

É importante, ainda, ressaltar que apesar das considerações e apontamentos apresentados, outros autores e lentes teóricas também são úteis para pensar a questão dos imigrantes, da ascensão da extrema direita europeia e os acontecimentos que se desenrolam dentro do bloco europeu. Outras conclusões e apontamentos podem ser feitos em relação ao tema e, por ser um assunto que está se desenrolando no momento, novos fatos e acontecimentos podem surgir para completar ou aumentar a observação feita aqui. Dessa forma, este artigo não tinha como objetivo esgotar o tema, mas de apenas trazer mais reflexões sobre o assunto e compreender o cenário político atual.

\section{REFERÊNCIAS BIBLIOGRÁFICAS}

ACNUR. (2020). Global Trends: Forced Displacement in 2020. Disponível em: https://www.unhcr.org/60b638e37/unhcr-global-trends-

2020\#_ga=2.13929407.906796874.1631493776-637520838.1572714918 [Acesso em: 12 Ago. 2021].

Akkerman, A. et al. (2017). "We the people' or 'we the peoples'? A comparison of support for the populist radical right and populist radical left in the Netherlands', Swiss Political Science Review, 23(4), pp. 377-403. 
Anderson, B. (2008). Comunidades Imaginadas. São Paulo: Companhia das Letras.

BBC. (2013). In graphics: Eurozone crisis, 25 de abril. Disponível em: https://www.bbc.com/news/business-13361934\# [Acesso em: 17 Jan. 2020].

BBC Brasil. (2008). Entenda a quebra do banco Lehman Brothers, 15 de setembro. Disponível em: https://www.bbc.com/portuguese/reporterbbc/story/2008/09/080915_lehman_qa_pu. shtml [Acesso em: 17 Jan. 2020].

BBC Brasil. (2018a). Como a Suécia se tornou o centro da extrema-direita e do supremacismo branco na Europa, 18 de fevereiro. Disponível em: https://www.bbc.com/portuguese/internacional-43062949. [Acesso em: 20 Jan. 2020].

BBC Brasil. (2018b). O avanço do Vox, o partido de direita que promete 'tornar a Espanha grande de novo', 03 de dezembro. Disponível em: https://www.bbc.com/portuguese/internacional-46424959 [Acesso em: 20 Jan. 2020]

Beck, U. (2015). 'Como a crise do euro dilacera - e - une a Europa', In: Beck, U. (2015). A Europa alemã: A crise do euro e as novas perspectivas de poder. São Paulo: Editora Paz e Terra. Disponível em: https://books.google.com.br/books/about/A_Europa_alem\%C3\%A3.html?id=k6fDCAAA QBAJ\&printsec $=$ frontcover\&source $=k p \_r e a d \_b u t t o n \& r e d i r \_e s c=y \# v=0 n e p a g e \& q \& f=f a l s$ e [Acesso em: 19 Jan. 2020].

Blikstad, N. M. D.; Oliveira, G. C. de. (2018). 'Instabilidade financeira na Eurozona e a crise dos títulos públicos dos GIIPS', Economia e Sociedade, Campinas, 27(2), pp. 431-462. Disponível em: http://www.scielo.br/pdf/ecos/v27n2/1982-3533-ecos-27-02-0431 [Acesso em: 19 Jan. 2020].

CNN. (2019). Donations flood in for migrant ship captain arrested for docking in Italy, 01 de julho. Disponível em: https://edition.cnn.com/2019/07/01/europe/sea-watchcaptain-fundraiser-scli-grm-intl/index.html [Acesso em: 21 Ago. 2021].

Corte Europeia de Direitos Humanos (1950). Disponível em: https://www.echr.coe.int/Documents/Convention_POR.pdf. [Acesso em: 21 de janeiro de 2020]

Dicionário Online. Definição de 'xenofobia'. Disponível em: https://www.dicio.com.br/xenofobia/

El País (2019). "Voltaria a fazer exatamente a mesma coisa", diz a capitã presa por salvar refugiados no mar, 11 de julho. Disponível em:

https://brasil.elpais.com/brasil/2019/07/10/internacional/1562776886_469320.html [Acesso em: 10 de julho 2021].

Held, D.; McGrew, A. (2001). Prós e Contras da Globalização. Rio de Janeiro: Jorge Zahar, Introdução e Capítulo 3. 
Heller, A. (2019). Por que a Hungria se rendeu ao extremista Orbán e como controlar o ensino é essencial para seu projeto, 23 de maio. Disponível em: https://brasil.elpais.com/brasil/2019/04/18/actualidad/1555585620_542476.html [Acesso em: 17 Jan. 2020].

Ignazi, P. (2003). Extreme Right Parties in Western Europe. Oxford: Oxford University Press.

KOLST $\varnothing$, P. (2016). 'The Ethinification of Russian nationalism', In: Kolst $\varnothing$, P.; Blakkisrud, H. (Eds.) The New Russian Nationalism. Imperialism, Ethnicity and Authoritarianism 200015, Edinburgh: Edinburgh University Press, pp. 104-131.

Nye, J.; Keohane, R. (1989). Power and interdependence. New York: Harper Collin, 2a Ed., Cap. 1.

O Estado de São Paulo (Estadão). (2012). Protestos marcam Dia do Trabalho na Espanha, Grécia, Portugal e França, 01 de maio. Disponível em: https://economia.estadao.com.br/noticias/geral,protestos-marcam-dia-do-trabalho-naespanha-grecia-portugal-e-franca 110854e [Acesso em: 19 Jan. 2020].

O Estado de São Paulo (Estadão). (2018). Itália adota decreto contra imigração que restringe proteção humanitária, 24 de setembro. Disponível em: https://internacional.estadao.com.br/noticias/geral,governo-italiano-adota-durodecreto-contra-imigracao, 70002516481 [Acesso em: 21 Jan. 2020].

ONU. (2018). Representante da ONU reforça críticas a declarações racistas de primeiroministro da Hungria, 06 de março. Disponível em: https://nacoesunidas.org/representante-da-onu-reforca-criticas-a-declaracoes-racistasde-primeiro-ministro-da-hungria/ [Acesso em: 17 Jan. 2020].

Skey, M.; Antonsich, M. (2017). 'Conclusion: The Present and Future of Nationalism', In: Skey, M.; Antonsich, M. (Eds.), Everyday Nationhood Theorising Culture, Identity and Belonging after Banal Nationalism, London: Palgrave Macmillan, pp.323 -334.

Soares, A. G. et al. (2020). 'Crises econômicas, ascensão da extrema direita e a relativização dos direitos humanos', Cadernos de Campo: Revista de Ciências Sociais, N. 28, p. $193-223$.

Swank, D.; Betz, H. (2002). 'Globalization, the Welfare State and Right-Wing Populism in Western Europe', Socio-Economic Review, Vol. 1, pp. 215-245.

The Guardian. (2013). France's headscarf war: 'It's an attack on freedom', 22 de julho. Disponível em: https://www.theguardian.com/world/2013/jul/22/frances-headscarfwar-attack-on-freedom [Acesso em: 17 Set. 2021].

Tostes, A. P. (2009). 'Razões da Intolerância na Europa Integrada', Dados - Revista de Ciências Sociais, 52(2), pp. 335-376. 
Verdú, D. (2018). Itália anuncia que fechará seus portos a barco de resgate com 600 migrantes, 10 de junho. Disponível em: https://brasil.elpais.com/brasil/2018/06/10/internacional/1528642309_207661.html. [Acesso em: 07 Jan. 2020].

Wæver, O. (1998). 'Security Analysis: Conceptual Apparatus', In: Wæver, O.; Buzan, B.; Wilde, J. de. Security: A New Framework for Analysis. Colorado: Lynne Rienner Publishers Inc, pp. 21-47.

Walker, R. B. J. (2010). After the Globe, Before the World. New York: Routledge.

Yotova, D. (2017). 'New forms of collective intentity in Europe', Journal of Liberty and International Affairs, 3 (supp. 1), pp. 55-73. 